\title{
Resposta do meloeiro à fertigação controlada através de íons da solução do solo: Parâmetros produtivos ${ }^{1}$
}

Manoel J. da Silva Júnior'2, Sergio N. Duarte³, Francisco de A. de O liveira ${ }^{3}$, José F. de Medeiros² \& Indalécio Dutra²

RESUMO

A fertigação tem-se desenvolvido muito e seu manejo que, é feito através do uso de curvas de absorção de nutrientes, começa a mudar para o monitoramento dos nutrientes na solução do solo. Buscou-se estudar, aqui, a resposta do meloeiro submetido a concentrações controladas de nitrogênio e potássio na solução do solo, através da adoção de 13 tratamentos dispostos em delineamento inteiramente aleatorizado com 4 repetições em que cada um foi aplicado através do manejo controlado das concentrações de nitrogênio e potássio na solução do solo. A cultura foi irrigada por gotejamento e a fertigação realizada somente quando necessário. Avaliaram-se o número de frutos, a produção, o peso médio dos frutos, a porcentagem de rendiIhamento da superfície dos frutos, o diâmetro dos frutos, a espessura e a firmeza da polpa e os sólidos solúveis totais e se realizou análise de variância e de regressão com o uso do SAS. Constataram-se baixa produção, peso médio de frutos e, em geral que, os frutos colhidos tiveram baixa qualidade. Obtiveram-se as melhores características de qualidade dos frutos em concentrações de nitrogênio na solução do solo entre 240 e $260 \mathrm{mg} \mathrm{L}^{-1}$, tendo o potássio variado entre a não aplicação em fertigação e $84 \mathrm{mg} \mathrm{L}^{-1}$.

Palavras-chave: Cucumis melo L., concentração iônica, extratores de cápsula porosa, nitrogênio, potássio

\section{Response of melon plants to fertigation controlled by ions of the soil solution: Yield parameters}

\begin{abstract}
Fertigation has developed considerably and its management, which is done through the use of the uptake curves of nutrients, begins to change for the monitoring of the nutrients in the soil solution. Thus, this work studied the response of melon plants subjected to controlled concentrations of nitrogen and potassium in the soil solution, by adopting 13 treatments disposed in fully randomized design with 4 replications. Each treatment was applied through the management of controlled concentrations of nitrogen and potassium in the soil solution. The crop was drip irrigated and the fertigation carried out only when necessary. The number of fruits, production, the average weight of fruit, the percentage of the area tracery fruit, the fruit diameter, thickness and firmness of flesh and the soluble solids were evaluated and analyses of variance and regression using the SAS were performed. Low yield and low average weight of fruits were verified and, in general, the fruits harvested were of low quality. The best features of the quality of fruits were obtained with concentrations of nitrogen in the soil solution between 240 and $260 \mathrm{mg} \mathrm{L}^{-1}$, and the potassium varied between non-application in fertigation and $84 \mathrm{mg} \mathrm{L}^{-1}$.
\end{abstract}

Key words: Cucumis melo L., ionic concentration, porous ceramic cup extractors, nitrogen, potassium

1Parte da Tese apresentada pelo primeiro autor à ESALQ/USP. Financiada com recursos do CNPq

2DCAT/UFERSA, BR 110, km 47, CP 137, CEP 59625-900, Mossoró, RN. Fone: (84) 3315-1740. E-mail: mjanuario@ufersa.edu.br; jfmedeir@ufersa.edu.br, idutra@ufersa.edu.br

32ESALQ/USP, Av. Pádua Dias 11, CP 09, CEP 13418-900, Piracicaba, SP. Fone: (19) 3447-8543. E-mail: snduarte@esalq.usp.br; thikaoamigao@hotmail.com 


\section{INTRODUÇÃO}

A aplicação de adubos via água de irrigação, é uma das atividades de maior desenvolvimento e crescimento na agricultura irrigada e deve ser feita de maneira racional, em consonância com as características de absorção de cada cultura em cada estádio de desenvolvimento, com as práticas culturais necessárias durante o ciclo produtivo, com a distribuição dos nutrientes no perfil do solo e com a eficiência do sistema de irrigação (Bar-Yosef, 1999).

Tradicionalmente, o manejo da fertigação é realizado por meio de quantidades preestabelecidas de fertilizantes, parceladas de acordo com a marcha de absorção da cultura e, normalmente, não existe monitoramento da concentração de íons na solução do solo nem do estado nutricional da planta resultando, em alguns casos, em gastos excessivos com fertilizantes e, em outros, na salinização dos solos.

$\mathrm{O}$ uso de extratores de solução do solo de cápsula porosa tem auxiliado no manejo da fertigação, permitindo identificar e contornar problemas causados por desequilíbrios nutricionais e processos de salinização.

Vários trabalhos têm sido desenvolvidos com o objetivo de estudar o uso de extratores de solução do solo para fins de manejo da fertigação (Blanco et al., 2008; Dias et al., 2005; Silva et al., 2000) com resultados promissores quanto ao uso dos extratores. Concluiu-se, daí, que o manejo da fertigação com o uso de extratores de solução de cápsula porosa se manifesta como alternativa econômica e ambiental; entretanto, ainda precisa ser estudado o manejo da fertigação com o controle da concentração dos íons específicos na solução do solo.

Dias et al. (2004) citam valores preliminares de concentrações adequadas de nitrato e potássio na solução do solo para as culturas do tomate, pimentão e pepino. Lao et al. (2004), em solo de casas de vegetação comerciais cultivadas com tomateiros, encontraram valores médios de nitrato e potássio, de 12,7 e 6,0 mmol $_{\mathrm{c}} \mathrm{L}^{-1}$, respectivamente.

Lao et al. (2003) encontraram um modelo linear simples para estimar a composição real da solução do solo a partir umidade do solo e da composição da solução do solo. Para os autores, este modelo pode ser usado no cálculo da composição de soluções nutritivas e também ser relevante na preparação de soluções balanceadas para fertigação, maximizando a produção e minimizando o uso excessivo de fertilizantes e a poluição em ecossistemas de horticultura intensiva.

Assim tem-se que, com o exposto, o objetivo desta pesquisa foi estudar a resposta produtiva da cultura do meloeiro quando submetida a diferentes concentrações controladas de nitrogênio-nitrato e potássio, na solução do solo.

\section{MATERIAL E MÉTODOS}

O experimento foi realizado em casa de vegetação, localizada no Campus da Universidade Federal Rural do Semiárido

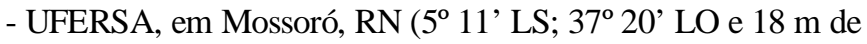
altitude), cujo clima fica assim caracterizado: $27,4^{\circ} \mathrm{C}$ de tem- peratura média, $673,9 \mathrm{~mm}$ de precipitação concentrando-se nos primeiros meses do ano e $68,9 \%$ de umidade relativa do ar.

Definiram-se os tratamentos a partir da combinação de cinco concentrações de nitrogênio-nitrato e cinco de potássio na solução do solo, através de uma matriz denominada quadrado duplo, formando 13 tratamentos; desta forma, os tratamentos de $\mathrm{N}^{-\mathrm{NO}_{3}}$ e K em relação a uma concentração considerada padrão (100\%) ficaram assim definidos: 0-0, 0-100, 0-200, 50-50, 50-150, 100-0, 100-100, 100-200, 150-50, 150-150, 200-0, 200-100, 200-200\%. O nível zero foi definido como o valor da concentração de $\mathrm{N}-\mathrm{NO}_{3}$ e $\mathrm{K}$ encontrada na solução do solo em condições naturais.

Utilizaram-se, como concentrações padrão de nitrogênionitrato e de potássio, as recomendadas para cultivo hidropônico do meloeiro (Castellane \& Araújo, 1994) ajustadas para 168 e $84 \mathrm{mg} \mathrm{L}^{-1}$, respectivamente.

$\mathrm{O}$ delineamento experimental adotado foi o inteiramente aleatorizado com 4 repetições, totalizando 52 parcelas, sendo que cada parcela foi representada por um vaso de plástico com aproximadamente $20 \mathrm{~L}$ de capacidade.

A cultura utilizada foi o meloeiro (Cucumis melo L.) do tipo cantaloupe, híbrido Dom Luiz da SAKATA, o qual possui ampla aceitabilidade nos mercados interno e externo.

O solo utilizado no experimento foi coletado em local ainda não cultivado, sendo classificado como Cambissolo Eutrófico, possuindo textura argilosa e as seguintes características físico-quimicas: $\mathrm{pH}-7,1$; M.O. - 1,7\%; P - 5,0 mg dm${ }^{-3}$; $\mathrm{K}-0,87 ; \mathrm{Na}-0,79 ; \mathrm{Ca}-4,00 ; \mathrm{Mg}-1,10 ; \mathrm{Al}-0,00 ; \mathrm{H}-2,48$ $\mathrm{mmol}_{\mathrm{c}} \mathrm{dm}^{-3} ; \mathrm{d}-1.300 \mathrm{~kg} \mathrm{~m}^{-3}$; areia - 45; silte - 25 e argila $30 \%$; depois de coletado o solo foi destorroado e acondicionado em vasos formados por baldes plásticos de $20 \mathrm{~L}$ de capacidade, compactando-o o suficiente para caber $24 \mathrm{~kg}$ de solo argiloso em cada vaso. Os vasos foram dispostos em linhas, no espaçamento de $1,0 \times 0,5$.

Realizou-se o plantio através de semeadura direta nos vasos, no dia 23 de abril de 2008, colocando-se quatro sementes por vaso cuja germinação se deu 5 dias depois.

Fez-se o desbaste após a germinação, deixando-se duas plantas por vaso até a fase de floração plena, quando uma planta foi retirada para ser avaliada e, a partir desta fase, uma planta foi conduzida até a produção. A cultura foi mantida no "limpo" fazendo-se tantas capinas quantas fossem necessárias. Adotou-se para o controle de pragas e doenças, o manejo preventivo utilizando-se produtos e formulações empregadas pelos produtores da região. A cultura foi tutorada verticalmente através de fitilhos amarrados a espaldeiras verticais instaladas ao longo da linha de plantio. Os ramos laterais localizados abaixo do primeiro fio da espaldeira $(0,40 \mathrm{~m}$ da superfície do vaso) foram desbrotados e os demais conduzidos, juntamente com a haste principal. A polinização foi manual, esfregando-se a flor masculina nas flores femininas e hermafroditas e os frutos foram acomodados em redes de nylon amarradas aos fios das espaldeiras.

A irrigação foi realizada por gotejamento, utilizando-se emissores do tipo espaguete com vazão controlada para 1,76 $\mathrm{L} \mathrm{h}^{-1}$, e em cada vaso se instalou um espaguete. $\mathrm{O}$ sistema de irrigação foi equipado com caixa d'água suspensa com nível controlado por boia, linha de derivação, válvulas manuais e 
linhas laterais. O manejo da irrigação se baseou em dados de tensão da água no solo, obtidos através de tensiômetros instalados a $0,20 \mathrm{~m}$ de profundidade, que foram convertidos em umidade com o auxílio da curva característica de retenção de água no solo (Figura 1); desta forma, as irrigações foram realizadas sempre para repor o volume de água necessário a fim de elevar a umidade do solo a umidade da capacidade de campo.

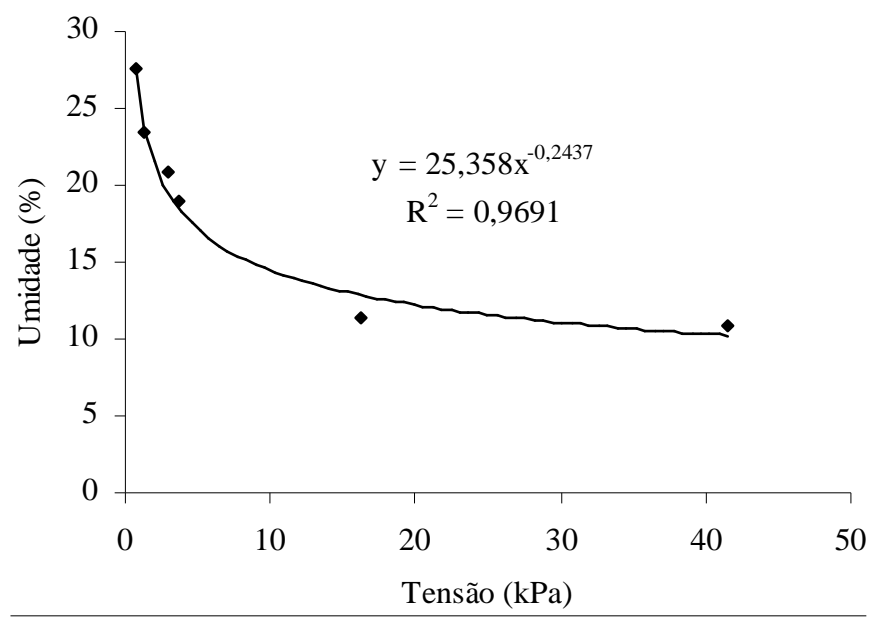

Figura 1. Ajuste da umidade do solo em função da tensão da água no solo

Obteve-se a solução do solo com extratores munidos de cápsulas cerâmicas em sua extremidade inferior e borrachas especiais com vedação de silicone na extremidade superior, os quais, por outro lado, foram instalados a 0,10 e $0,20 \mathrm{~m}$ de profundidade e a eles foi promovida uma tensão de aproximadamente $80 \mathrm{kPa}$, através da sucção do ar contido no seu interior. A solução extraída foi acondicionada em recipientes plásticos para posterior análise; as análises de nitrogênio-nitrato foram realizadas com o uso de uma cartela de teste rápido da marca Horiba, enquanto as de potássio foram analisadas através da fotometria de emissão de chama.

A solução do solo foi coletada sempre antes da irrigação, ocasião em que se mediu a tensão da água no solo para se corrigir as concentrações medidas dos nutrientes para a umidade da capacidade de campo, como demonstrado em Silva Júnior (2008).

Ao solo se aplicou, antes do plantio, uma solução fertilizante contendo todos os macronutrientes em volume suficiente para elevar a umidade do solo a umidade da capacidade de campo. Ajustou-se a concentração de nitrogênio e potássio através de curvas de calibração dos tratamentos (Figura 2) para disponibilizar, na solução do solo, a concentração desejada para cada tratamento, enquanto os demais nutrientes permaneceram constantes, com a seguinte composição: $\mathrm{P}$ - 31; Ca - 160; Mg - 24 e S - 32 mg L-1.

Realizaram-se, ao longo do ciclo, as aplicações dos fertilizantes nitrogenados e potássicos de acordo com a concentração de nitrogênio e potássio na solução do solo, tal como demonstrado em Silva Júnior (2008).

Os adubos contendo fósforo, cálcio, magnésio e enxofre, foram suprimidos nos primeiros 50 dias e, posteriormente,

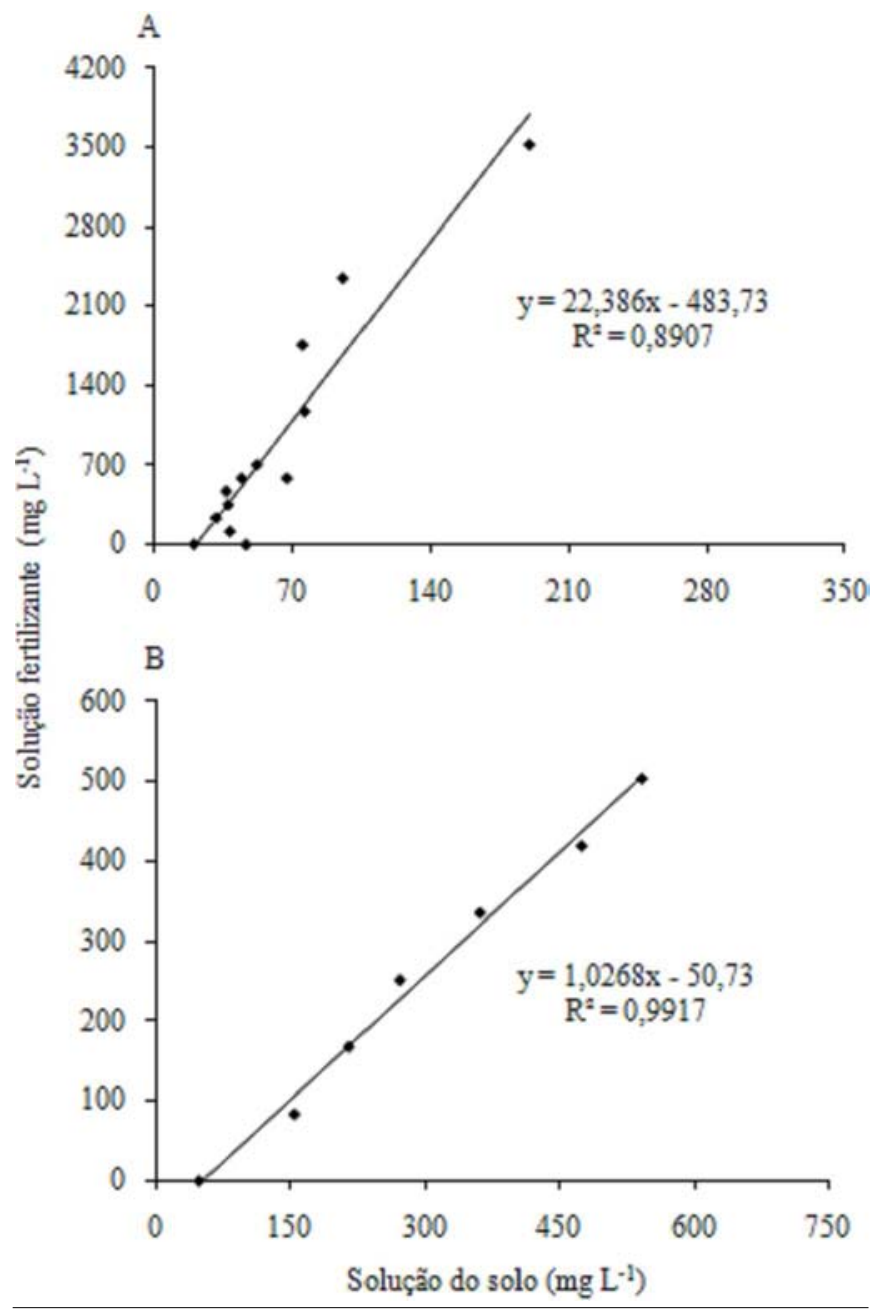

Figura 2. Ajuste da concentração de potássio (A) e nitrogênio (B) na solução fertilizante em função da concentração de nitrogênio e potássio na solução do solo

aplicados em todos os eventos de fertigação nas concentrações inicialmente adicionadas.

O volume de solução aplicado em cada evento de fertigação foi o suficiente para elevar a umidade atual do solo a umidade da capacidade de campo. As fertirrigações foram feitas manualmente, com proveta, para medir o volume de solução; quando não foi necessário aplicar adubo aplicou-se apenas água, através do sistema de irrigação.

Utilizaram-se, como fertilizantes, os seguintes produtos: nitrato de cálcio, cloreto de potássio, fosfato monobásico de potássio, nitrato de potássio, nitrato de sódio, cloreto de cálcio, sulfato de magnésio e ácido fosfórico.

Os parâmetros produtivos e de qualidade avaliados, foram: o número de frutos, a produção, o peso médio dos frutos, a porcentagem rendilhamento da superfície dos frutos, o diâmetro dos frutos, a espessura e a firmeza da polpa e os sólidos solúveis totais ( ${ }^{\circ}$ Brix).

Para determinação do número de frutos fez-se a contagem da quantidade de frutos produzidos por cada planta; para produção, os frutos produzidos por cada planta foram pesados; para o peso médio de frutos, fez-se a relação entre a produção e o número de frutos; para porcentagem de rendilhamento da superfície do fruto, fez-se uma avaliação visual 
da superfície do fruto, ocasião em que dois avaliadores deram notas variando de zero a cem por cento para cada fruto avaliado; para espessura da polpa, abriu-se o fruto longitudinalmente e se mediu transversalmente, a polpa na região equatorial do fruto; para a firmeza da polpa, mediu-se a resistência exercida por um penetrômetro com pluger de ponta cônica de $8 \mathrm{~mm}$ de diâmetro na polpa do fruto; para os sólidos solúveis totais determinou-se $\mathrm{o}{ }^{\circ} \mathrm{Brix}$ da polpa do fruto com refratômetro digital, pressionando-se uma fatia do fruto nas regiões polares, até saírem algumas gotas que foram coletadas no sensor do refratômetro.

Realizaram-se as análises de variância e de regressão desdobrando-se todos os graus de liberdade dos tratamentos em efeitos de regressão lineares e quadráticos e em interações entre esses efeitos; com os efeitos de regressão significativos $(\mathrm{p} \leq 0,05)$, ajustou-se a equação de regressão para explicar o comportamento dos dados. Em todas essas análises foram utilizados os procedimentos do aplicativo SAS. As estimativas dos parâmetros dos modelos ajustados foram submetidas ao teste $\mathrm{F}$ com o auxílio do aplicativo FCalcw para identificar o nível de significância de cada parâmetro em função do quadrado médio do resíduo da análise de variância, considerados significativos aqueles com $\mathrm{p} \leq 0,05$.

\section{RESULTADOS E DISCUSSÃO}

\section{Produção e componentes da produção}

A produção de frutos observada foi influenciada pelas concentrações de nitrogênio e pelas concentrações de potássio. A produção aumentou linearmente quando as concentrações de nitrogênio e potássio foram aumentadas na solução do solo, tendo havido, ainda, efeitos quadráticos e de interações para os dois fatores, com o que a função ajustada assume um valor máximo de $602,94 \mathrm{~g}$ por planta, dentro do intervalo de estudo, para o valor de concentração na solução do solo de $336 \mathrm{mg} \mathrm{L}^{-1}$ de nitrogênio e sem aplicação de potássio em fertigação (Tabela 1).

Não houve efeito de $\mathrm{N}$ e K sobre o número de frutos, cuja média observada foi de 1,05 frutos por planta (Tabela 1).

Tendo em vista que não houve significância no número de frutos e que a média desta variável ficou próxima de um, o peso médio dos frutos apresentou praticamente o mesmo comportamento da produção, ou seja, aumentou juntamente com o incremento das concentrações de nitrogênio e potássio na solução do solo tendo havido, ainda, efeitos quadráticos e de interações, sendo que o peso médio máximo obtido pela função ajustada $(771,5 \mathrm{~g})$ foi obtido com o uso dos maiores níveis de nitrogênio e de potássio, ou seja, 336 e 84 mg $\mathrm{L}^{-1}$, respectivamente (Tabela 1).

Com relação à produção, Andriolo et al. (2005) estimaram que as concentrações em solução nutritiva de $273 \mathrm{mg} \mathrm{L}^{-1} \mathrm{e}$ $351 \mathrm{mg} \mathrm{L}^{-1}$, respectivamente, de nitrato e de potássio resultariam em produtividade máxima para o meloeiro de aproximadamente $2.000 \mathrm{~g}$ por planta; para o pepino, Costa et al. (2001), concluíram que o menor teor de potássio, $45 \mathrm{mg} \mathrm{L}^{-1}$, foi suficiente para atingir alta produção. Considerando que esses
Tabela 1. Produção total, número de frutos por planta e peso médio dos frutos das plantas de meloeiro "cantaloupe", em função da concentração de nitrogênio $(\mathrm{N})$ e potássio $(K)$ na solução do solo

\begin{tabular}{|c|c|c|c|c|c|c|}
\hline \multirow{2}{*}{$\begin{array}{l}\text { Concentração } \\
\text { de N (mg L-1) }\end{array}$} & \multicolumn{5}{|c|}{ Concentração de $\mathrm{K}\left(\mathrm{mg} \mathrm{L}^{-1}\right)$} & \multirow{2}{*}{ Média } \\
\hline & 0 & 21 & 42 & 63 & 84 & \\
\hline \multicolumn{7}{|c|}{ Produção total (g planta-1 $\left.{ }^{-1}\right)$} \\
\hline 0 & 281,25 & - & 233,25 & - & 221,50 & 245,33 \\
\hline 84 & - & 368,50 & - & 506,50 & - & 437,50 \\
\hline 168 & 359,50 & - & 605,75 & - & 441,00 & 468,75 \\
\hline 252 & - & 515,00 & - & 530,25 & - & 522,63 \\
\hline 336 & 621,75 & - & 404,75 & - & 586,75 & 537,75 \\
\hline Média & 420,83 & 441,75 & 414,58 & 518,38 & 416,42 & 442,39 \\
\hline Equação: & \multicolumn{5}{|c|}{$\begin{array}{c}Y=202,14 * *+1,59 * * N+6,05^{* *} K-0,0012^{n s} N^{2}- \\
0,071^{* *} K^{2}-0,00012^{* *} N^{2} K+0,00011^{\text {ns }} N K 2+ \\
0,0000011^{* *} N^{2} K^{2}\end{array}$} & $R^{2}=0,968$ \\
\hline \multicolumn{7}{|c|}{ Número de frutos por planta } \\
\hline 0 & 1,00 & - & 1,16 & - & 1,00 & 1,04 \\
\hline 84 & - & 1,00 & - & 1,00 & - & 1,00 \\
\hline 168 & 1,19 & - & 1,20 & - & 1,00 & 1,12 \\
\hline 252 & - & 1,00 & - & 1,00 & - & 1,00 \\
\hline 336 & 1,17 & - & 1,13 & - & 1,00 & 1,10 \\
\hline Média & 1,13 & 1,00 & 1,17 & 1,00 & 1,00 & 1,05 \\
\hline \multicolumn{6}{|c|}{ Não houve variabilidade estatística nos dados } & \\
\hline \multicolumn{7}{|c|}{ Peso médio dos frutos $(\mathrm{g})$} \\
\hline 0 & 281,25 & - & 201,63 & - & 221,50 & 234,79 \\
\hline 84 & - & 368,50 & - & 506,50 & - & 437,50 \\
\hline 168 & 303,25 & - & 506,63 & - & 441,00 & 416,96 \\
\hline 252 & - & 515,00 & - & 530,25 & - & 522,63 \\
\hline 336 & 529,75 & - & 357,50 & - & 586,75 & 491,33 \\
\hline Média & 371,42 & 441,75 & 355,25 & 518,38 & 416,42 & 420,64 \\
\hline Equação: & \multicolumn{5}{|c|}{$\begin{array}{c}Y=252,00 * *+1,42 * * N+0,60^{n s} K-0,0024 * * N^{2}- \\
0,010^{n \text { ns }} K^{2}+0,00012^{*} N K^{2}+0,00000020^{n s} N^{2} K^{2}\end{array}$} & $R^{2}=0,901$ \\
\hline
\end{tabular}

estudos foram realizados em sistema hidropônico, por não haver a matriz do solo interferindo, as concentrações encontradas poderiam ser diferentes daquelas estimadas neste estudo, onde foi utilizado solo; entretanto, as produções deveriam ser semelhantes, o que não aconteceu.

Em condições semelhantes às deste experimento, Monteiro et al. (2008) encontraram produções por planta, próximas a $3.000 \mathrm{~g}$, e Dias et al. (2006) notaram máximo rendimento total de $987 \mathrm{~g}$ por planta para o primeiro ciclo e $1.031 \mathrm{~g}$ por planta para o segundo ciclo; assim, todas as produções observadas por outros autores estão acima daquelas encontradas neste estudo, o que indica que as plantas poderiam ter tido produções maiores, o que sugere ter havido alguma limitação para o seu bom desenvolvimento.

Com relação ao peso médio dos frutos, Andriolo et al. (2003), obtiveram valor próximo ao deste estudo (715 g) para soluções com concentração $168 \mathrm{mg} \mathrm{L}^{-1}$ de nitrogênio e 222 $\mathrm{mg} \mathrm{L}^{-1}$ de potássio; entretanto, Monteiro et al. (2008), que trabalharam em condições parecidas com as deste experimento, constataram valores superiores (1.360 a $1.440 \mathrm{~g}$ ), indicando que as plantas poderiam ter produzido frutos mais pesados. Deste particular, pode-se observar que todas as características de produção avaliadas indicam que as plantas 
conduzidas neste trabalho tiveram menor desempenho que as plantas de outros estudos.

Considerando uma densidade de plantio de 20.000 plantas por hectare e a produção máxima obtida pela função ajustada de 602,94 g por planta, seria possível obter, para essas condições, uma produtividade de aproximadamente $12.000 \mathrm{~kg} \mathrm{ha}^{-1}$ já próxima à obtida por Dias et al. (2006) no primeiro ciclo (14.860 kg ha-1); entretanto, bem abaixo dos valores observados por outros autores (Andriolo et al., 2003; Soares, 2001).

\section{Qualidade da produção}

Uma das características de qualidade mais importantes para o melão cantaloupe é o rendilhamento da superfície do fruto, pois ela fica visível ao consumidor, no ato da compra; observou-se para esta característica (Tabela 2) efeito do nitrogênio e do potássio de forma linear, quadrática e de interações; para o nitrogênio, o rendilhamento da superfície aumentou e, para o potássio, a superfície do fruto teve seu rendilhamento diminuído com o aumento das concentrações desses nutrientes na solução do solo. Como a interação quadrática foi significativa, a ocorrência de um máximo e um mínimo ao mesmo tempo, conhecido como ponto de cela, remete o valor máximo da função para as bordas da superfície do fator que reduz a variável; assim, o maior rendilhamento da superfície do fruto $(92,06 \%)$ foi obtido com a manutenção de $240 \mathrm{mg} \mathrm{L}^{-1}$ de nitrogênio na solução do solo e com a não aplicação de adubos potássicos em fertigação $\left(0 \mathrm{mg} \mathrm{L}^{-1}\right)$.

Tabela 2. Rendilhamento da superfície do fruto das plantas de meloeiro "cantaloupe", em função da concentração de nitrogênio $(\mathrm{N})$ e potássio $(\mathrm{K})$ na solução do solo

\begin{tabular}{|c|c|c|c|c|c|c|}
\hline \multirow{2}{*}{$\begin{array}{l}\text { Concentração } \\
\text { de } N\left(m g L^{-1}\right)\end{array}$} & \multicolumn{5}{|c|}{ Concentração de $K\left(\mathrm{mg} \mathrm{L}^{-1}\right)$} & \multirow{2}{*}{ Média } \\
\hline & 0 & 21 & 42 & 63 & 84 & \\
\hline \multicolumn{7}{|c|}{ Rendilhamento da superfície do fruto (\%) } \\
\hline 0 & 62,50 & - & 7,50 & - & 70,00 & 46,67 \\
\hline 84 & - & 87,50 & - & 95,00 & - & 91,25 \\
\hline 168 & 55,00 & - & 91,25 & - & 77,50 & 74,58 \\
\hline 252 & - & 98,75 & - & 87,50 & - & 93,13 \\
\hline 336 & 90,00 & - & 75,00 & - & 95,00 & 86,67 \\
\hline Média & 69,17 & 93,13 & 57,92 & 91,25 & 80,83 & 78,46 \\
\hline Equação: & \multicolumn{6}{|c|}{$\begin{array}{c}Y=43,62 * *+0,40 * * N-0,21^{n s} K-0,00083 * * N^{2}+ \\
0,0056 * * K^{2}-0,000028 * N K^{2}+0,000000060 * N^{2} K^{2}\end{array}$} \\
\hline
\end{tabular}

${ }^{*} \mathrm{e}^{* *}$ : Significativo a 5 e a $1 \%$ de probabilidade, respectivamente. ns: não significativo

Para esta variável, Vargas et al. (2008) observaram que, quando se cultivou o melão em substrato, os frutos apresentaram rendilhamento mais intenso em relação aos cultivados no solo e o rendilhamento observado variou entre médio e intenso, o que pode ser entendido como entre 50 e $100 \%$; assim, pode-se considerar que o rendilhamento da superfície dos frutos estimada pela função ajustada, pode ser considerado ótimo.

O diâmetro dos frutos aumentou com as concentrações de nitrogênio e de potássio na solução do solo. Observaram-se, ainda, efeitos quadráticos e de interações, sendo que o valor máximo de diâmetro obtido pela função ajustada, da ordem de $10,25 \mathrm{~cm}$, ocorreu ao se utilizar as concentrações de 260 e $84 \mathrm{mg} \mathrm{L}^{-1}$, respectivamente de nitrogênio e potássio (Tabela 3).

Tabela 3. Diâmetro do fruto das plantas de meloeiro "cantaloupe", em função da concentração de nitrogênio (N) e potássio (K) na solução do solo

\begin{tabular}{|c|c|c|c|c|c|c|}
\hline \multirow{2}{*}{$\begin{array}{l}\text { Concentraçãa } \\
\text { de } \mathrm{N}\left(\mathrm{mg} \mathrm{L}^{-1}\right)\end{array}$} & \multicolumn{5}{|c|}{ Concentração de $K\left(\mathrm{mg} \mathrm{L}^{-1}\right)$} & \multirow{2}{*}{ Média } \\
\hline & 0 & 21 & 42 & 63 & 84 & \\
\hline \multicolumn{7}{|c|}{ Diâmetro do fruto $(\mathrm{cm})$} \\
\hline 0 & 7,73 & - & 7,20 & - & 7,25 & 7,39 \\
\hline 84 & - & 8,43 & - & 9,85 & - & 9,14 \\
\hline 168 & 8,15 & - & 10,05 & - & 9,23 & 9,14 \\
\hline 252 & - & 9,88 & - & 10,10 & - & 9,99 \\
\hline 336 & 9,78 & - & 8,07 & - & 9,80 & 9,21 \\
\hline Média & 8,55 & 9,15 & 8,44 & 9,98 & 8,76 & 8,97 \\
\hline Equação: & \multicolumn{5}{|c|}{$\begin{array}{c}Y=6,99 * *+0,015^{* *} \mathrm{~N}+0,048^{* *} \mathrm{~K}- \\
0,000021^{* *} \mathrm{~N}^{2}-0,00055^{* *} \mathrm{~K}^{2}-0,00000088^{* *} \mathrm{~N}^{2} \mathrm{~K}+ \\
0,0000013^{*} \mathrm{NK}^{2}+0,000000007^{* *} \mathrm{~N}^{2} \mathrm{~K}^{2}\end{array}$} & $R^{2}=0,938$ \\
\hline
\end{tabular}

${ }^{*} \mathrm{e}^{* *}$ : Significativo a 5 e a $1 \%$ de probabilidade, respectivamente. ${ }^{\text {ns: não }}$ significativo

O diâmetro máximo dos frutos encontrado neste experimento, ficou abaixo daquele observado por Follegatti et al. (2004), que variou de 13,2 a 14,0 cm, e acima do obtido por Soares (2001), que foi de $9,5 \mathrm{~cm}$.

Constatou-se observado efeito quadrático das concentrações de nitrogênio e de potássio sobre a espessura da polpa dos frutos; mas não se observaram efeitos das interações. A espessura aumentou com a concentração de nitrogênio até atingir um valor máximo e diminuiu com o incremento na concentração de potássio até atingir um valor mínimo; com isto, o valor máximo obtido com a função ajustada foi de $2,70 \mathrm{~cm}$ para as condições de manutenção de $255 \mathrm{mg} \mathrm{L}^{-1}$ de nitrogênio na solução do solo e para não aplicação de potássio em fertigação (Tabela 4).

Tabela 4. Espessura da polpa dos frutos de meloeiro "cantaloupe", em função da concentração de nitrogênio (N) e potássio (K) na solução do solo

\begin{tabular}{|c|c|c|c|c|c|c|}
\hline \multirow{2}{*}{$\begin{array}{l}\text { Concentração } \\
\text { de } N\left(\mathrm{mg} \mathrm{L}^{-1}\right)\end{array}$} & \multicolumn{5}{|c|}{ Concentração de $\mathrm{K}\left(\mathrm{mg} \mathrm{L}^{-1}\right)$} & \multirow{2}{*}{ Média } \\
\hline & 0 & 21 & 42 & 63 & 84 & \\
\hline \multicolumn{7}{|c|}{ Espessura da polpa (cm) } \\
\hline 0 & 2,04 & - & 1,30 & - & 1,81 & 1,72 \\
\hline 84 & - & 2,48 & - & 2,46 & - & 2,47 \\
\hline 168 & 2,23 & - & 2,65 & - & 2,24 & 2,37 \\
\hline 252 & - & 2,60 & - & 2,83 & - & 2,71 \\
\hline 336 & 2,66 & - & 2,31 & - & 2,75 & 2,58 \\
\hline Média & 2,31 & 2,54 & 2,09 & 2,64 & 2,27 & 2,37 \\
\hline Equação: & \multicolumn{5}{|c|}{$\begin{aligned} Y= & 1,82 * *+0,0068 * * N-0,0034^{n s} K- \\
& 0,000013 * * N^{2}+0,000038^{n s} K^{2}\end{aligned}$} & $R^{2}=0,657$ \\
\hline
\end{tabular}

$\mathrm{e}^{* * *}$ : Significativo a 5 e a $1 \%$ de probabilidade, respectivamente. ${ }^{\text {ns: }}$ não significativo

Monteiro et al. (2008) encontraram espessura de polpa variando de 3,7 a $3,9 \mathrm{~cm}$, enquanto Folegatti et al. (2004) notaram valores mínimo e máximo de espessura da polpa com 2,8 e $3,8 \mathrm{~cm}$, respectivamente e, para Soares (2001), os maiores valores médios de espessura da polpa variaram de 3,1 a 
$3,3 \mathrm{~cm}$. Observa-se, então, que a espessura da polpa máxima estimada é inferior aos valores encontrados por outros autores; como o diâmetro dos frutos encontrado neste estudo foi bem próximo dos valores observados em estudos semelhantes, a diferença observada para o peso médio dos frutos pode ter sido devida à menor espessura da polpa.

A firmeza da polpa cresceu com o aumento das concentrações de nitrogênio até atingir valor máximo; por outro lado, a firmeza diminuiu quando se aumentaram as concentrações de potássio, ocorrendo também o efeito quadrático. Considerando a ocorrência de interações, a função ajustada assumiu o valor máximo de $9,66 \mathrm{~N}$ para a manutenção de $250 \mathrm{mg} \mathrm{L}^{-1} \mathrm{de}$ nitrogênio na solução do solo e para a não aplicação de potássio em fertigação, isto é, $0 \mathrm{mg} \mathrm{L}^{-1}$ (Tabela 5).

Tabela 5. Firmeza da polpa dos frutos de meloeiro "cantaloupe", em função da concentração de nitrogênio $(\mathrm{N})$ e potássio (K) na solução do solo

\begin{tabular}{|c|c|c|c|c|c|c|}
\hline \multirow{2}{*}{$\begin{array}{l}\text { Concentração } \\
\text { de } N\left(\mathrm{mg} \mathrm{L}^{-1}\right)\end{array}$} & \multicolumn{5}{|c|}{ Concentração de $\mathrm{K}\left(\mathrm{mg} \mathrm{L}^{-1}\right)$} & \multirow{2}{*}{ Média } \\
\hline & 0 & 21 & 42 & 63 & 84 & \\
\hline \multicolumn{7}{|c|}{ Firmeza da polpa (N) } \\
\hline 0 & 5,66 & - & 5,44 & - & 2,11 & 4,40 \\
\hline 84 & - & 7,33 & - & 3,91 & - & 5,62 \\
\hline 168 & 8,98 & - & 8,75 & - & 10,08 & 9,27 \\
\hline 252 & - & 8,75 & - & 6,50 & - & 7,62 \\
\hline 336 & 8,47 & - & 10,00 & - & 5,41 & 7,96 \\
\hline Média & 7,70 & 8,04 & 8,06 & 5,20 & 5,86 & 6,97 \\
\hline Equação: & \multicolumn{5}{|c|}{$\begin{array}{c}Y=5,07 * *+0,036^{* *} N-0,012^{n s} K-0,000072^{* *} N^{2} \\
-0,00013^{n s} K^{2}-0,0000000010^{n s} N^{2} K^{2}\end{array}$} & $R^{2}=0,766$ \\
\hline
\end{tabular}

Folegatti et al. (2004) encontraram valores de firmeza de polpa variando de 4,45 a 17,51 N. Monteiro et al. (2008) notaram firmeza da polpa na faixa de 2,99 a 3,12 N. Em Dias et al. (2006) os valores de textura variaram de 19,93 a 17,45 N; esta variável depende do estádio de maturação em que os frutos são colhidos podendo variar bastante. Se os frutos são colhidos em estádio de maturação mais avançado, a firmeza é menor e a concentração de sólidos solúveis totais (SST) é maior mas a vida útil pós-colheita é menor. Se o fruto for colhido mais cedo, a firmeza aumenta e SST diminui; entretanto, a vida útil aumenta e, em assim sendo, o estudo da firmeza de polpa está relacionado com o estudo de SST devendo-se, pois, buscar um equilíbrio para ambas as variáveis.

A concentração de sólidos solúveis totais expressa na forma de graus brix para os frutos do meloeiro, variou com as concentrações de nitrogênio e de potássio na solução do solo; SST reduziu gradativamente com o aumento da concentração de N e atingiu um valor mínimo; por outro lado, o SST aumentou com a concentração de potássio na solução do solo e, em virtude das interações observadas, o maior valor de SST ( $9,51^{\circ}$ Brix) foi obtido com o uso dos maiores níveis de nitrogênio e de potássio na solução do solo $\left(336\right.$ e $84 \mathrm{mg} \mathrm{L}^{-1}$, respectivamente) (Tabela 6).

Dias et al. (2006) encontraram valores médios de 8,07 e 11,10 ${ }^{\circ}$ Brix, respectivamente, nos primeiro e segundo ciclos. Para Soares (2001), os valores médios de sólidos solúveis totais
Tabela 6. Sólidos solúveis totais da polpa dos frutos de meloeiro "cantaloupe", em função da concentração de nitrogênio (N) e potássio (K) na solução do solo

\begin{tabular}{|c|c|c|c|c|c|c|}
\hline \multirow{2}{*}{$\begin{array}{l}\text { Concentração } \\
\text { de } N\left(m ~^{-1}\right)\end{array}$} & \multicolumn{5}{|c|}{ Concentração de $\mathrm{K}\left(\mathrm{mg} \mathrm{L}^{-1}\right)$} & \multirow{2}{*}{ Média } \\
\hline & 0 & 21 & 42 & 63 & 84 & \\
\hline \multicolumn{7}{|c|}{ Sólidos solúveis totais ('Brix) } \\
\hline 0 & 6,83 & - & 5,25 & - & 7,93 & 6,67 \\
\hline 84 & - & 8,05 & - & 10,43 & - & 9,24 \\
\hline 168 & 6,03 & - & 5,95 & - & 5,40 & 5,79 \\
\hline 252 & - & 6,68 & - & 8,53 & - & 7,60 \\
\hline 336 & 7,05 & - & 6,53 & - & 9,88 & 7,82 \\
\hline Média & 6,63 & 7,36 & 5,91 & 9,48 & 7,73 & 7,42 \\
\hline Equação: & \multicolumn{6}{|c|}{ 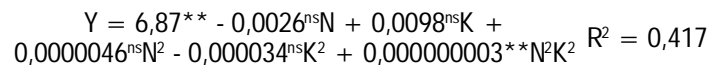 } \\
\hline
\end{tabular}

variaram de 9,8 a $12,8{ }^{\circ}$ Brix; já Monteiro et al. (2008), notaram teor de sólidos solúveis totais na faixa de 11,36 a $12,03{ }^{\circ}$ Brix, enquanto Folegatti et al. (2004), trabalhando com o mesmo híbrido, encontraram valores entre 6,99 e 13,25 ${ }^{\circ}$ Brix.

O valor máximo estimado de SST se encontra ligeiramente abaixo da faixa de valores, observada por outros autores. Considerando que a firmeza e a espessura da polpa se encontravam também abaixo da faixa observada, pode-se dizer que os frutos colhidos não estavam dentro dos padrões da cultura, necessitando de melhoria de qualidade para alcançar melhor valor comercial.

\section{CONCLUSÕES}

1. Observou-se baixa produção e peso médio de frutos, sendo que os maiores valores foram obtidos com a concentração na solução do solo de $336 \mathrm{mg} \mathrm{L}^{-1}$ de nitrogênio e potássio variando entre a não aplicação em fertigação e $84 \mathrm{mg} \mathrm{L}^{-1}$.

2. Obtiveram-se os valores máximos das características de qualidade dos frutos com concentrações de nitrogênio na solução do solo entre 240 e $260 \mathrm{mg} \mathrm{L}^{-1}$, tendo-se observado concentrações para o potássio entre não aplicação em fertigação e $84 \mathrm{mg} \mathrm{L}^{-1}$.

3. A maioria das características de qualidade dos frutos colhidos apresentou valores abaixo dos padrões da cultura, sendo necessária uma melhoria de qualidade para se alcançar melhor valor comercial.

\section{AGRADECIMENTOS}

Ao Conselho Nacional de Desenvolvimento Científico e Tecnológico - CNPq, pela concessão de auxílio financeiro para realização da pesquisa, e à Universidade Federal Rural do Semiárido - UFERSA, pela concessão da infraestrutura.

\section{LITERATURA CITADA}

Andriolo, J. L.; Lanzanova, M. E.; Witter, M. Produtividade de frutos de meloeiro cultivado em substrato com três soluções nutritivas. Horticultura Brasileira, v.21, n.3, p.478-481, 2003. 
Andriolo, J. L.; Luz, G. L.; Bortolotto, O. C.; Godoi, R. S. Produtividade e qualidade de frutos de meloeiro cultivado em substrato com três doses de solução nutritiva. Ciência Rural, v.35, n.4, p.781-787, 2005.

Bar-Yosef, B. Advances in fertigation. Advances in Agronomy, v.65, p.1-77, 1999.

Blanco, F. F.; Folegatti, M. V.; Henriques Neto, D. Doses de N e $\mathrm{K}$ no tomateiro sob estresse salino: I. Concentração de nutrientes no solo e na planta. Revista Brasileira de Engenharia Agrícola e Ambiental, v.12, n.1, p.26-33, 2008.

Castellane, P. D.; Araújo, J. A. C. Cultivo sem solo: Hidroponia. Jaboticabal: FUNEP, 1994. 43p.

Costa, P. C.; Cañizares, K. A. L.; Goto, R. Produção de pepino de plantas enxertadas cultivadas em soluções nutritivas com diferentes teores de potássio. Horticultura Brasileira, v.19, n.3, p.207-209, 2001.

Dias, N. S.; Duarte, S. N.; Gheyi, H. R.; Medeiros, J. F. de; Soares, T. M. Manejo da Fertirrigação e controle da salinidade do solo sob ambiente protegido, utilizando-se extratores de solução do solo. Revista Brasileira de Engenharia Agrícola e Ambiental, v.9, n.4, p.496-504, 2005.

Dias, N. S.; Duarte, S. N.; Medeiros, J. F. de; Teles Filho, J. F. Salinidade e manejo da fertirrigação em ambiente protegido II: efeitos sobre o rendimento do meloeiro. Irriga, v.11, n.3, p.376-383, 2006.

Dias, N. S.; Duarte, S. N.; Silva, E. F. F.; Folegatti, M. V. Manejo da fertirrigação utilizando extratores de solução do solo. Piracicaba: ESALQ/USP, 2004. 23p. Série produtor rural, 25
Folegatti, M. V.; Vásquez, M. A. N.; Dias, N. S. da; Sousa, V. F. de. Qualidade física do melão fertirrigado com diferentes dosagens de potássio e lâminas de irrigação, em gotejamentos superficial e subsuperficial. Irriga, v.9, n.1, p.52-61, 2004.

Lao, M. T.; Jiménez, S.; Eymar, E.; Fernández, E. J. Nutrient levels of the solution obtained by means of suction cups in intensive tomato cultivation. Phyton, v.4, n.7, p.29-37, 2004.

Lao, M. T.; Jiménez, S.; Eymar, E.; Fernández, E. J.; Jiménez, R. Determination of spatial variability of nutrient composition of Soil solutions in greenhouses by using suction cups. Communications in soil science and Plant Analysis, v.34, n. 5/6, p. 865-879, 2003.

Monteiro, R. O. C.; Coelho, R. D.; Melo, P. C. T.; Ferraz, P.; Chaves, S. W. P.; Shirahige, F.H.; Beltrame Neto, E.; Piedade, S. M. $S$. Net melon performance as affected by the drip irrigation depth and mulching. Horticultura Brasileira, v.26, p. 447-451, 2008.

Silva, E. F. F.; Anti, G. R.; Carmello, Q. A. C.; Duarte, S. N. Extratores de cápsulas porosas para o monitoramento da condutividade elétrica e do teor de potássio na solução de um solo. Scientia Agricola, v.57, n.4, p.785-789, 2000.

Silva Júnior, M. J. Manejo da fertirrigação na cultura do meloeiro mediante o controle de íons da solução do solo. Piracicaba: ESALQ/USP, 2008. 114p. Tese Doutorado

Soares, A. J. Efeitos de três lâminas de irrigação e de quatro doses de potássio via fertirrigação no meloeiro em ambiente protegido. Piracicaba: ESALQ/USP, 2001. 63p. Dissertação Mestrado

Vargas, P. F.; Castoldi, R.; Charlo, H. C. O.; Braz, L. T. Qualidade de melão rendilhado (Cucumis melo L.) em função do sistema de cultivo. Ciência e Agrotecnologia, v.32, n.1, p.137-142, 2008. 